\title{
Dose-dependent effect of black mustard seeds (Brassica nigra) extract on the prefrontal cortex of adult Wistar rats
}

\author{
Tolulope Timothy Arogundade ${ }^{1,2}$, Bernard Ufuoma Enaibe ${ }^{1,2}$, Oluwaseun Olaniyi Adigun ${ }^{2}$, \\ Foyeke Munirat Adigun ${ }^{2}$, Ismail Temitayo Gbadamosi ${ }^{2}$ \\ ${ }^{I}$ Department of Anatomy, Faculty of Basic Medical Sciences, Adeleke University, Ede, Nigeria \\ ${ }^{2}$ Department of Anatomy, Faculty of Basic Medical Sciences, University of Ilorin, Ilorin, Nigeria
}

\begin{abstract}
Objectives: Mustard seeds, apart from being a culinary essential, have had medicinal applications dating back to the time of Hippocrates. It has in fact been once mentioned as the greatest herb ever. We explored the dose dependent effects of the crude aqueous extract of Brassica nigra (Black mustard seeds) on the prefrontal cortex of adult Wistar rats.

Methods: 20 adult female rats weighing an average of $180 \pm 20 \mathrm{~g}$ were used. They were split into 4 groups ( $n=5$ ); Group A (received extract at $200 \mathrm{mg} / \mathrm{kg}$ body weight), Group B (received extract at $100 \mathrm{mg} / \mathrm{kg}$ body weight), Group C (received extract at $50 \mathrm{mg} / \mathrm{kg}$ body weight), and Group D (received distilled water ad libitum). All of the animals were subjected to the Y-maze spontaneous alternation test for neurobehavioural analyses following 28-day administration of the extracts. Animals were sacrificed 24 hours after taking the last day of administration.

Results: Our results showed that neurobehavioural analyses are significantly hampered in animals receiving $200 \mathrm{mg} / \mathrm{kg}$ extract in comparison to the control group. In treatment groups, increased dose of extract elevated the level of MDA, but reduced the level of SOD. LDH levels were also significantly increased in the $200 \mathrm{mg} / \mathrm{kg}$ treated group when comparing with the control. General microarchitecture in the prefrontal cortex of $200 \mathrm{mg} / \mathrm{kg}$ Brassica nigra treated group showed signs of karyolysis and pyknosis.
\end{abstract}

Conclusion: Brassica nigra (black mustard) is not innocuous and therefore it should be consumed in moderation.

Keywords: Brassica nigra; neurobehaviour; neurototoxicity; prefrontal cortex

Anatomy 2017;11(3):107-114 @2017 Turkish Society of Anatomy and Clinical Anatomy (TSACA)

\section{Introduction}

Mustard seeds are the tiniest part of the mustard plant which flourishes in the cold weather, moist soil and general temperate conditions. The plant grows as a shrub while the seeds are about two millimeters in diameter and used as spices in many countries. ${ }^{[1]}$ There are approximately 40 different varieties of mustard plants, but the three principal ones which also vary in color are Brassica birta or alba (yellow-white), Brassica nigra (black) and Brassica juncea (brown). Mustard seeds, apart from being a culinary essential, have had medicinal applications dating back to the time of Hippocrates. ${ }^{[2]}$ It is used by people all over the world. It has in fact been once mentioned as the greatest herb ever. It is used in cancer treatment and prevention, as well as has antidiabetic, antioxidant and antimicrobial properties. ${ }^{[3,4]}$ These and many more therapeutic potentials have been widely attributed to the presence of selenium in the plant. Magnesium and B-complex vitamins are also among its major constituents. ${ }^{[5]}$ It is however important to note that despite these widely acclaimed great healing properties of mustard seeds, information regarding safety and efficacy is lacking as well as some other forms of contraindications and interactions. This is the rationale for this research with the prefrontal cortex (PFC) being the focal point. The prefrontal cortex is the part of the brain responsible for executive functions/decisions as well as complex cognitive processes. ${ }^{[6]}$ The cells of the PFC are arranged as a six-layered structure. The most superficial is 
the cell-poor molecular layer and the deepest is the multiform (polymorphic) layer, which is populated largely by fusiform cells. Between these two layers, there are four layers that are alternatively mostly populated by stellate or pyramidal cells. The executive functions of the frontal cortex involve the ability to recognize future consequences resulting from current actions, to choose between good and bad actions (or better and best), override and suppress unacceptable social responses, and determine similarities and differences between things or events. ${ }^{[7]}$ Therefore, it is involved in higher mental functions. The frontal cortex also plays an important role in retaining long-term memories which are not task-based. These are memories associated often with emotions derived input from the limbic system. The frontal cortex modifies those emotions to generally fit socially acceptable norms. ${ }^{[7]}$ Thus, we specifically examined the dose-dependent effects of aqueous Brassica nigra seed extracts on the cognitive and memory functions, oxidative parameters, and finally, the histology of the PFC in Wistar rats. We examined the oxidative damage by assessing the level of superoxide dismutase (SOD), malondialdehyde (MDA) and lactate dehydrogenase $(\mathrm{LDH})$ enzymes.

\section{Materials and Methods}

All protocols and treatment procedures were done according to the Institutional Animal Care and Use Committee (IACUC) guidelines and as approved by the Faculty of Basic Medical Sciences Ethics Review Committee, University of Ilorin, Nigeria. Twenty (20) adult female Wistar rats with an average weight of $180 \pm 20 \mathrm{~g}$ were purchased from a private animal holding in Ilorin and used for the research. These rats were kept in the animal house of the Faculty of Basic Medical Sciences, University of Ilorin. The rats had liberal access to rat chow and water.

Animals were randomly assigned into 4 groups (A-D), each consisting of 5 rats. The groups were treated as follows: Group A received $200 \mathrm{mg} / \mathrm{kg}$ of extract daily for 28 days; Group B received $100 \mathrm{mg} / \mathrm{kg}$ for 28 days; Group C received $50 \mathrm{mg} / \mathrm{kg}$ for 28 days, and Group D received distilled water for 28 days. The rats were weighed twice a week ( 72 hours of intervals), beginning from the first day of administration using a digital weighing balance.

Mustard seeds were obtained from a local market in Ilorin. It was certified true by the department of Plant Biology at the University of Ilorin. The extract was prepared according to the method described by Inyang et al. ${ }^{[8]}$ The mustard seeds (Brassica nigra) were pulverized into powder with an electric blender. Three hundred grams $(300 \mathrm{~g})$ of the ground seeds was soaked in $1000 \mathrm{ml}$ of distilled water; stirred and left for 72 hours in a refrigerator at $4^{\circ} \mathrm{C}$. The mixture was sieved and filtered with Whatman No.1 filter paper. The resultant filtrate was dried in a water bath at $40^{\circ} \mathrm{C}$ for 96 hours to get the concentrate which was then diluted to stock. The extract was administered via the oral route. Proper volume was ensured through the use of a calibrated syringe fitted with an oral cannula.

Y-maze spontaneous alternation test was used to assess working and cognitive memory in rodents. Alternation behavior is based on the natural tendency in rodents to explore the maze systematically entering each arm in turn. Alternation behavior is then defined as consecutive entries into each of the three arms without repetition. This was examined using a Y-maze composed of three equally spaced arms $\left(120^{\circ}, 41 \mathrm{~cm}\right.$ long and $15 \mathrm{~cm}$ high). The floor of each arm is made of plywood and is $5 \mathrm{~cm}$ wide. Briefly, each rat was placed in one of the arm compartments and was allowed to move freely until its tail completely enters another arm. The sequence of arm entries was manually recorded with a video camera, the arms being labeled A, B, or C. An alternation is defined as entry into all three arms consecutively, for instance if the animal makes the following arm entries; A, C, B, C, A, B, C, A, C, A, B, C, A, in this example, the animal made 13 arm entries 8 of which are correct alternations. The number of maximum spontaneous alternations is then the total number of arms entered minus two, and the percentage alternation is calculated as [(actual alternations/maximum alternations) $\times 100$ ]. For each animal in a group the Y-maze testing was carried out for 5 minutes, three trials and recorded for later analyses. The videos were analyzed by a neutral observer to eliminate bias.

After completion of treatments, rats were euthanized using $20 \mathrm{mg} / \mathrm{kg}$ of ketamine (i.p.) for histological analysis. Transcardiac perfusion was done by exposing the left ventricle and injecting $50 \mathrm{ml} \mathrm{0.1} \mathrm{M} \mathrm{PBS} \mathrm{(pH} \mathrm{7.4)} \mathrm{followed} \mathrm{by}$ $400 \mathrm{ml}$ 4\% paraformaldehyde (PFA) while the rat was suspended in an inverted position (gravity). Dissected brains were then rinsed in $0.25 \mathrm{M}$ sucrose 3 times for 5 minutes each and then post fixed in 4\% PFA for 24 hours before being stored in $30 \%$ sucrose at $4^{\circ} \mathrm{C}$ until further processing. Rats for enzymatic assays were sacrificed by separating the head from the trunk, to avoid the interference of ketamine with biochemical redox; brains were then excised, rinsed in $0.25 \mathrm{M}$ sucrose 3 times for 5 minutes each and placed in $30 \%$ sucrose in which they were stored at $4^{\circ} \mathrm{C}$. Coronal sections of PFC and hippocampus were obtained according to stereotaxic coordinates $(+4 \mathrm{~mm})$ from each brain. Histological staining was carried out in paraffin wax embedded sections which were stained with Haematoxylin and Eosin (H\&E) using the methods described by Fischer et al. ${ }^{[9]}$ Histochemical demonstration of Nissl substances was done with slight modification to the method published by Kádár et al. ${ }^{[0]}$ 
Determination of SOD, LDH and MDA activities was carried out on whole brains of treated rats using spectrophotometric technique. Each of the assay kits were procured from Bio Legend Inc., San Diego, CA, USA. Whole brain (in sucrose at $4^{\circ} \mathrm{C}$ ) from rats across groups were weighed and pulverized in $0.25 \mathrm{M}$ sucrose (Sigma) with the aid of an automated homogenizer at $4^{\circ} \mathrm{C}$. Lysates from the brain were centrifuged for 10 minutes in a microcentrifuge at 12,000 rpm to obtain the supernatant containing organelle fragments and synaptosomes. The supernatants were aspirated into plain labeled glass cuvette placed in ice. $\mathrm{SOD}, \mathrm{LDH}$ and MDA activities were assayed according to the manufacturer's instruction in the assay kit pack.

PFC sections on glass slides were captured using Olympus binocular research microscope (Olympus, Morristown, NJ, USA) which was connected to a 5.0 MP Amscope Camera (Amscope Inc, Irvine, CA, USA).

All quantitative data were analyzed using GraphPad Prism v.6 (GraphPad Software, Inc., La Jolla, CA, USA) and SPSS (Statistical Package for the Social Sciences, version 20.0; IBM, Chicago, IL, USA) software. Body weight, brain weight, spontaneous alternation, lactate dehydrogenase (LDH), malondialdehyde (MDA), and superoxide dismutase (SOD) outcomes were plotted in ANOVA followed with Tukey's multiple comparisons test. Significance was set at $\mathrm{p}<0.05$ and $\mathrm{p}<0.01$. The results were represented in bar charts with error bars to show the mean and standard error of mean $($ mean $\pm \mathrm{SEM})$ respectively.

\section{Results}

\section{Body and brain weights of experimental animals}

As described in the methods section, the body weight changes of the experimental rats was monitored and evaluated at a 72-hour interval following the beginning of administration and differences were examined by the analysis of variance (ANOVA). At the end of the first week of administration, there was a significant $(\mathrm{p}<0.05)$ increase in the body weight of animals treated with $200 \mathrm{mg} / \mathrm{kg}$ and 100 $\mathrm{mg} / \mathrm{kg}$ Basilica nigra seed extracts compared to the control (Figure 1). Body weight gain of the low dosage group (50 $\mathrm{mg} / \mathrm{kg}$ ) was not significantly different than those of control group. During the following weeks of administration, differences in the body weights of animals among the experimental groups were abolished. The mean brain weight of treated animals was not significantly different than control groups (Figure 2).

\section{Y-maze test results display dose dependence}

The correct percentage alternation in Group A, which received the extract at the dosage of $200 \mathrm{mg} / \mathrm{kg}$ body weight revealed a significant reduction $(\mathrm{p}<0.05)$ in comparison to the control (Figure 3). However, rats received

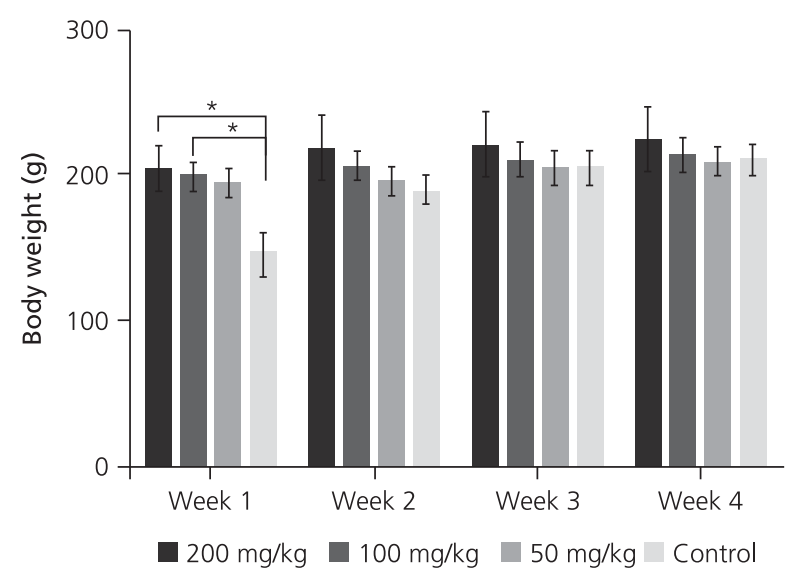

Figure 1. Analysis of the body weight of animals through the experimental duration. The first week of administration caused a significant increase in the body weight of animals in Group A (200 mg/kg) and Group B $(100 \mathrm{mg} / \mathrm{kg})$ relative to the control. Subsequent changes in weight of experimental animals were statistically insignificant comparatively. Values are represented as mean \pm SEM; ${ }^{*} p<0.05$.

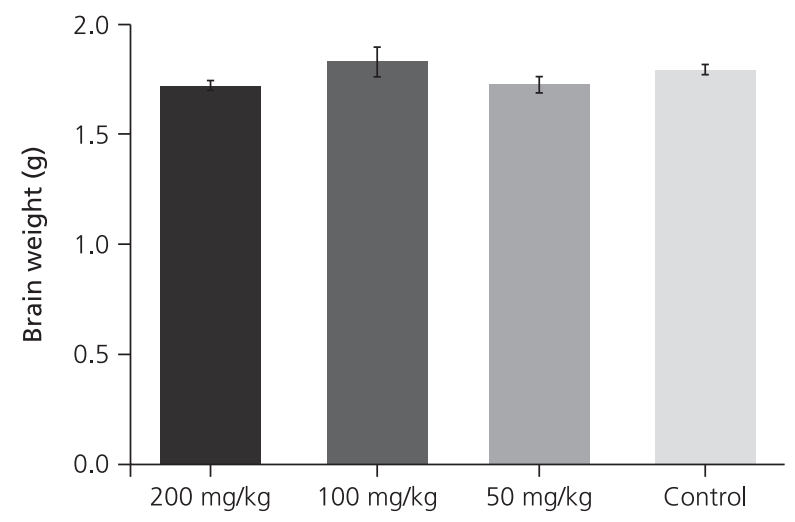

Figure 2. Analysis of the whole brain weight of animals. No significant difference was observed among the groups. Values are represented as mean \pm SEM.

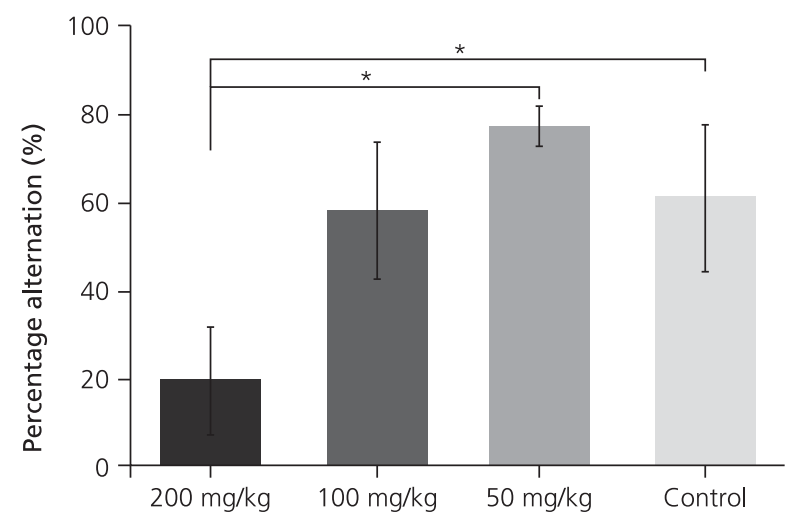

Figure 3. Analysis of percentage correct alternation in the $\mathrm{Y}$-maze test Relative to the control group, Basilica nigra at $200 \mathrm{mg} / \mathrm{kg}$ doses resulted in a significant depletion in \% correct alternation $(p<0.05)$. There was no significant change in the $100 \mathrm{mg} / \mathrm{kg}$ and $50 \mathrm{mg} / \mathrm{kg}$ Basilica nigra groups relative to the control. Values are represented as mean $\pm S E M ; ~ * p<0.05$. 
the extract at $50 \mathrm{mg} / \mathrm{kg}$ body weight dosages seemed to perform usually better in the alternation test in compared to those of the control. However, this observation was statistically insignificant. Group B that is received the extract at the dose of $100 \mathrm{mg} / \mathrm{kg}$ body weight was displayed relatively similar performance to the control group (Group D).

\section{Alterations in the oxidative damage markers}

MDA profiles displayed an augmentation in the treatment groups in parallel to the increasing dose of Brassica nigra extract, but this increase was not significantly different than those of the control group (Figure 4).

\section{High dose Brassica nigra treatment associates with LDH overexpression}

LDH is expressed extensively in body tissues during tissue damage. LDH level was significantly increased $(\mathrm{p}<0.01)$ in animals who received Brassica nigra extract at $200 \mathrm{mg} / \mathrm{kg}$ body weight dose) when compared with the control and low dose treatment groups (Figure 5). In animals receiving the a mild dose of $(100 \mathrm{mg} / \mathrm{kg}$ body weight) extract there was also a slight increase, but it was not enough to be statistically significant in comparison to the control group. These results showed some consistence with earlier findings of this study, suggesting the involvement of Basilica nigra in cellular damage. The levels of LDH enzyme in animals received the low dose (50 $\mathrm{mg} / \mathrm{kg}$ body weight) of the extract was comparable to the control animals (Figure 5).

\section{SOD profiles decreases following Brassica nigra administration}

Differential expression of SOD was assessed in the brain tissues of treated rats. Results from spectrophotometric assay showed that SOD levels in the low $(50 \mathrm{mg} / \mathrm{kg}$ body weight) and medium (100 mg/kg body weight) dose treatment groups increased in comparison to the control, but this rise was not significantly different. SOD level in the high dose group ( $200 \mathrm{mg} / \mathrm{kg}$ body weight), on the other hand was significantly lower than those of other groups (Figure 6).

\section{Histological changes in the prefrontal cortical areas}

The cellular anatomy of the prefrontal cortex in the control, low $(50 \mathrm{mg} / \mathrm{kg})$ and medium $(100 \mathrm{mg} / \mathrm{kg})$ doses of treatment with Brassica nigra seeds extract groups were dominated by large neurons characterized by the distinct pyramidal shape of their soma (Figure 7). However, Brassica nigra seeds extract at the $200 \mathrm{mg} / \mathrm{kg}$ body weight

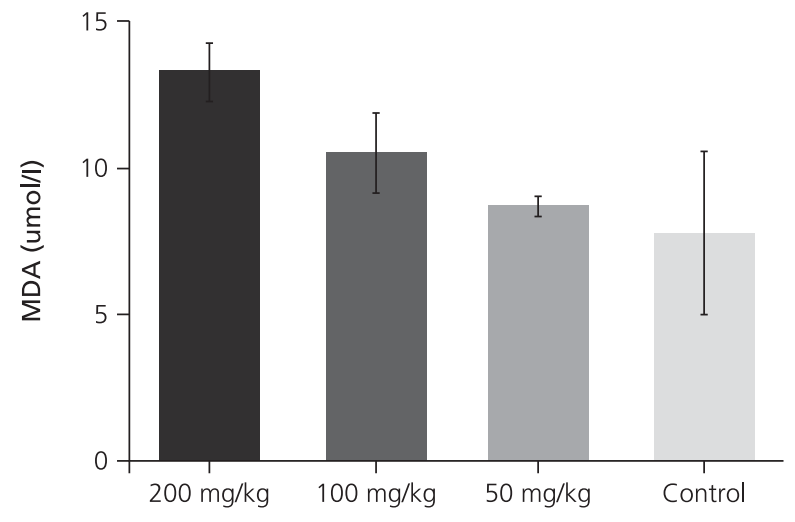

Figure 4. Analysis of MDA profile in the brain. Brain lysates from rats treated with Basilica nigra showed a dose-wise, but statistically insignificant, increase in MDA expression compared to that observable in the control group. Values are represented as mean \pm SEM.

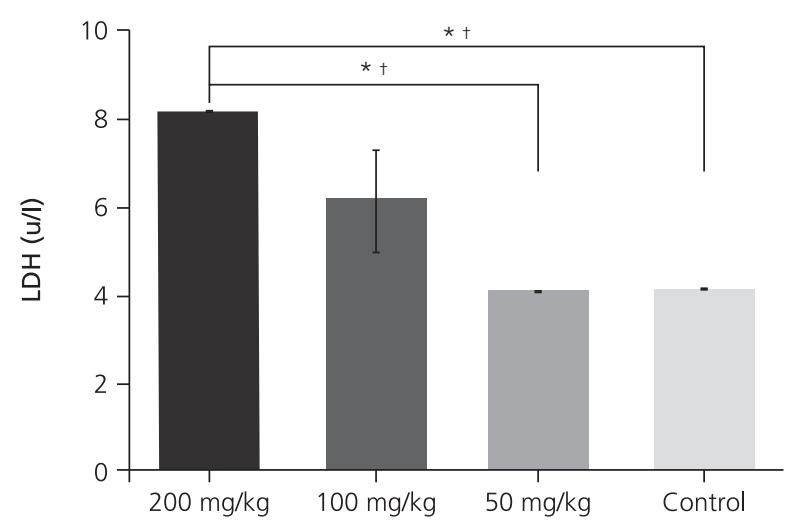

Figure 5. Analysis of brain LDH levels. $200 \mathrm{mg} / \mathrm{kg}$ Basilica nigra treatment resulted insignificant overexpression of $\mathrm{LDH}$ compared to the control group. Values are represented as mean \pm SEM; ${ }^{*} p<0.05 ;{ }^{\dagger} p<0.01$.

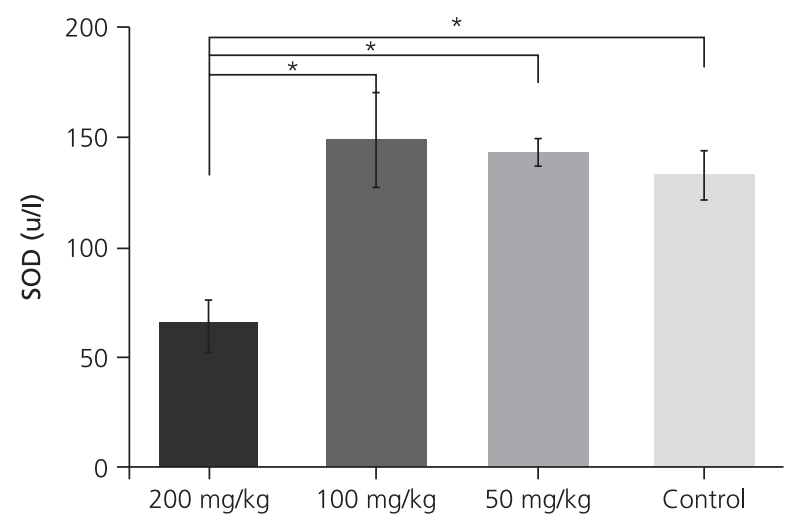

Figure 6. Analysis of SOD levels. Basilica nigra treatment at $200 \mathrm{mg} / \mathrm{kg}$ revealed marked depletion in brain SOD levels relative to the control. Values are represented as mean \pm SEM; ${ }^{*} p<0.05$. 
doses induced microarchitectural damages in the prefrontal cortex of animals by displaying properties of early stage apoptosis characterized by karyolysis and pyknosis. On histologic examination with H\&E staining, apoptosis involves single cells or small clusters of cells as shown by the dotted circles around the degenerating neurons in the $200 \mathrm{mg} / \mathrm{kg}$ treated group and the apoptotic cell appears as a round or oval mass, with dark eosinophilic cytoplasm and dense purple nuclear chromatin frag- ments. Furthermore, the cryptic changes seen in the soma of pyramidal neurons of the $200 \mathrm{mg} / \mathrm{kg}$ adult treated group also suggests apoptotic mode of neuronal cell death, in which cell shrinkage made the cells smaller in size, with dense cytoplasm and the organelles more tightly packed. Cresyl fast violet staining for Nissl substance, on the other hand, revealed a reduction in the staining intensity across all Basilica nigra treated groups in comparison to the control group (Figure 8).
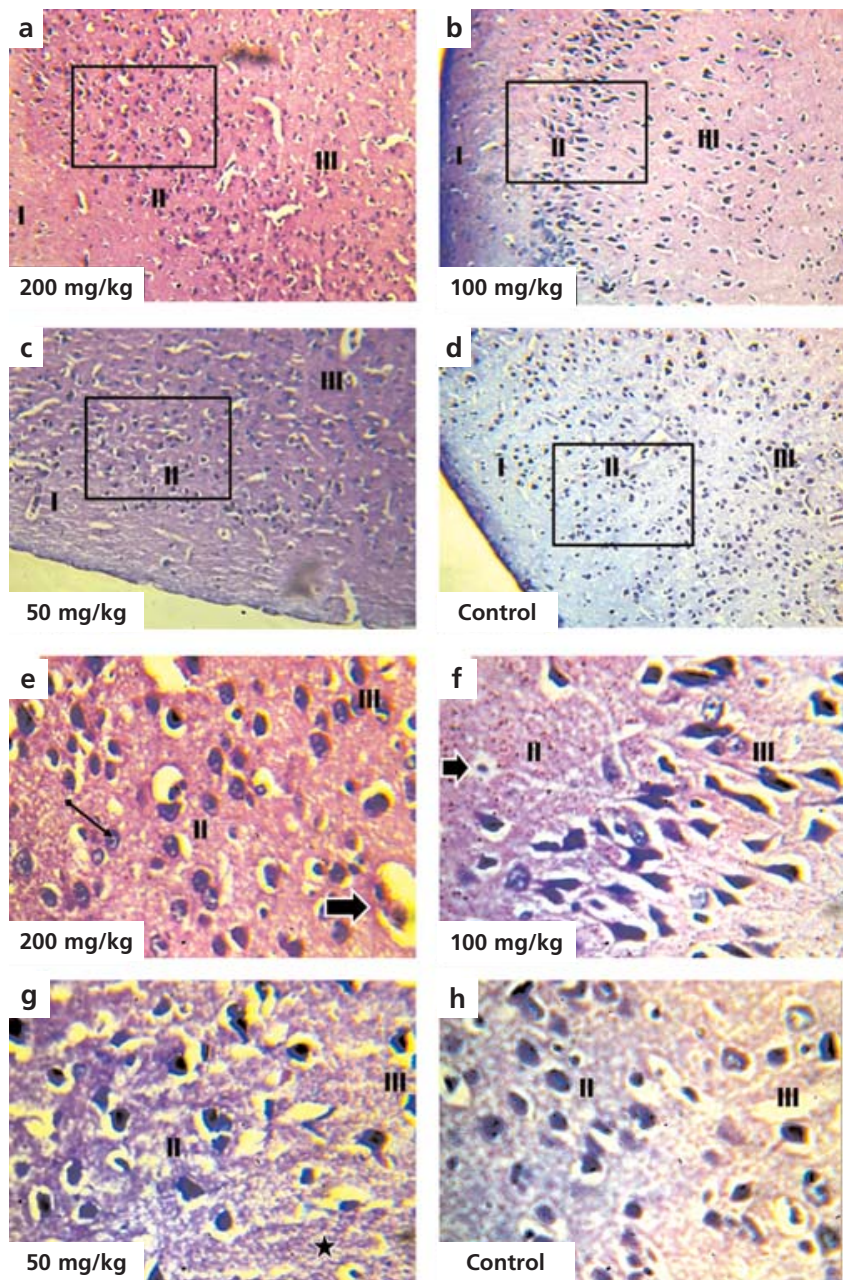

Figure 7. Histological analysis of PFC morphology revealed by H\&E staining (a-d: $\times 100$, e-h: $\times 400)$. (a) $200 \mathrm{mg} / \mathrm{kg}$, (b) $100 \mathrm{mg} / \mathrm{kg}$, and (c) 50 mg/kg Basilica nigra, (d) control. The molecular layer (I), external granular layer (II), and external pyramidal layer (III) are shown across study groups. PFC cytoarchitecture of the control group are in normal array and succinctly layered, while PFC neuropil especially in the 200 $\mathrm{mg} / \mathrm{kg}$ Basilica nigra group appeared charred, characterized by several fragmentations with a number of vacuolated cells (thick black arrow), dark pyknotic neurons (thin black arrows) and charred neuropil (star). [Color figure can be viewed in the online issue, which is available at www.anatomy.org.tr]
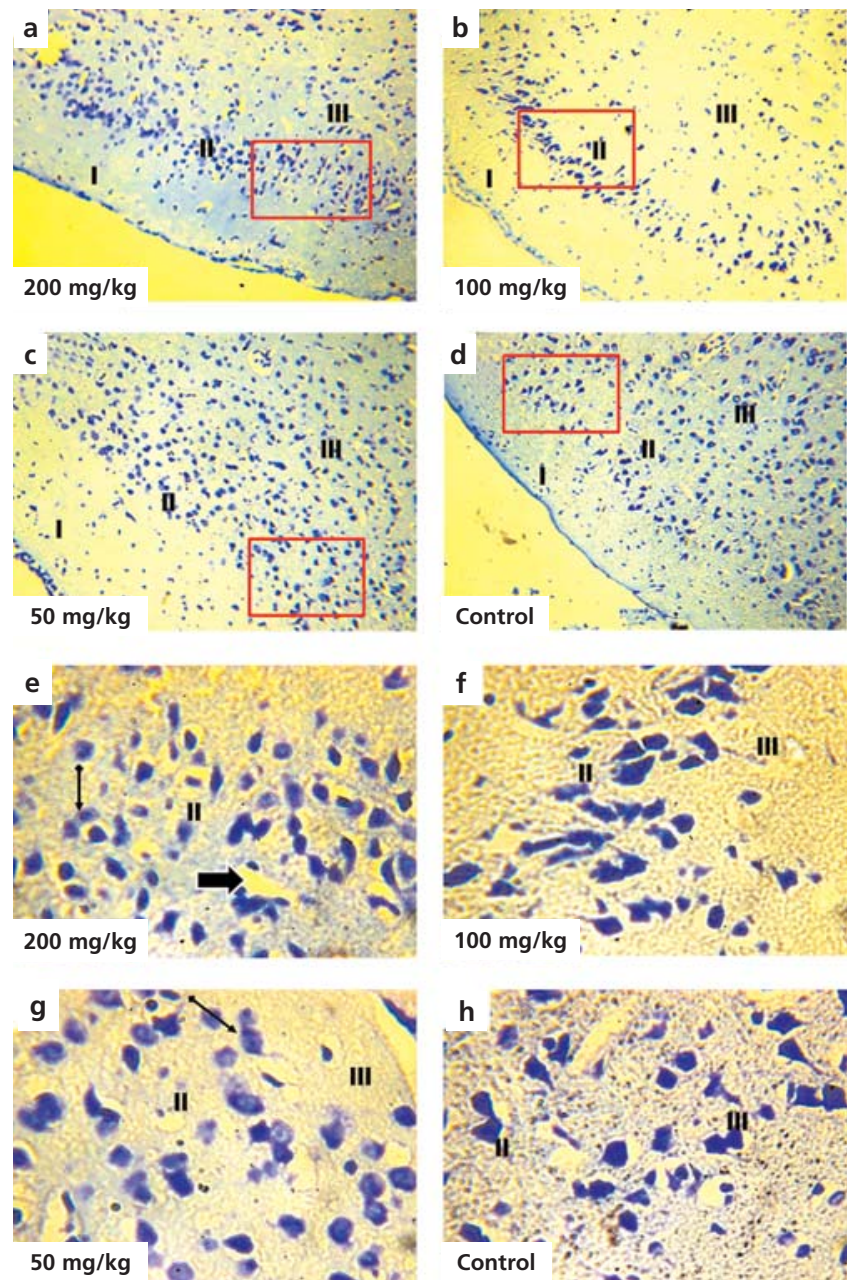

Figure 8. Histochemical demonstration of PFC morphology in treated rats shown in cresyl fast violet for Nissl substance (a-d: $\times 100, \mathbf{e}-\mathbf{h}: \times 400)$. (a) $200 \mathrm{mg} / \mathrm{kg}$, (b) $100 \mathrm{mg} / \mathrm{kg}$, and (c) $50 \mathrm{mg} / \mathrm{kg}$ Basilica nigra, (d) control. Similar to histological observations, control group appear morphologically normal and densely populated by Nissl proteins (cytoplasmic basophilic masses). Pyramidal neurons with notable processes are observable within the neuropil of the control group. Intensity of staining appears to be low across Basilica nigra treated groups. Cells with condensed irregular nuclei and peripheral vacuolation (thick black arrow), cells with low number of Nissl granules (thin arrows). [Color figure can be viewed in the online issue, which is available at www.anatomy.org.tr] 


\section{Discussion}

Mustard seeds have been used for medicinal applications dating back to the time of Hippocrates. It has been largely greeted for its healing properties and indicated as a potential cure-all. As early as 1699 , it was claimed that mustard seed could strengthen the memory, expel heaviness, and revive the spirits. Mustard seed was recommended in 1653 for toothaches, joint pain, skin problems, and stomach aches. ${ }^{[2]}$ This present study investigated the effects of Brassica nigra (black mustard) on the prefrontal cortex of adult Wistar rats at different doses $(200 \mathrm{mg} / \mathrm{kg}$, $100 \mathrm{mg} / \mathrm{kg}$, and $50 \mathrm{mg} / \mathrm{kg}$ ).

At the end of the first week of administration, there was a significant increase in the body weight gains of animals treated with the doses of $200 \mathrm{mg} / \mathrm{kg}$ and $100 \mathrm{mg} / \mathrm{kg}$ seeds extracts in comparison to the control. The following weeks of administration, we saw subtle increases in the body weight of each experimental group. Mustard seeds have been attributed to the appetite stimulating properties $^{[11]}$ and this might be the probable reason for the increment in the body weight of animals in a dosedependent manner. Appetite is the psychological desire to eat, and it is controlled by the lateral nucleus of the hypothalamus. ${ }^{[12]}$ It is sometimes triggered by hunger, but many times it is due to cravings, habits, the availability of food, boredom or other social and emotional factors. It is possible that the crude aqueous Brassica nigra seeds extract might stimulate the hypothalamic lateral nuclei and the appetite of animals to an extent that the animals eat not really out of hunger, but from the mere availability of food, and this could be the reason for the higher weight gain across treatment groups when compared with the control group. Kumar et al. similarly reported an increased weight gain in animals treated with Brassica nigra at $500 \mathrm{mg} / \mathrm{kg}$ and $1000 \mathrm{mg} / \mathrm{kg}$ when compared with the control in their experiment assessing the antihyperglycemic and antioxidant activity of Brassica nigra oil in streptozotocin-induced diabetic rats. They, however, used the oil extract from the Brassica nigra seeds. ${ }^{[13]}$ Following sacrification, the average brain weights of animals across groups were measured and significant difference was observed in the mean brain weights of animals treated with Brassica nigra seeds extract.

Evaluation of the behavioral outcomes provides important cues in assessing the effects of the treatment. As a correlative test for cellular, molecular and neuropathological changes within the PFC in this study, we assessed alternation behavior in treated rats. Y-maze spontaneous alternation test is used for the behavioral assessment, based on the natural tendency of rodents in exploring the maze systematically and entering the each arm in turn.
The result of this test revealed a significant reduction in the correct percentage alternation in animals receiving the extract at $200 \mathrm{mg} / \mathrm{kg}$ body weight doses when compared with the control group. Animals that received the extract at $50 \mathrm{mg} / \mathrm{kg}$ doses had a slightly higher, but not statistically significant, correct percentage alternation score in comparison to the control group. Group B that received the extract at $100 \mathrm{mg} / \mathrm{kg}$ doses was relatively at par with the control group. These results showed that at a relatively low to moderate doses $(50 \mathrm{mg} / \mathrm{kg}$ and $100 \mathrm{mg} / \mathrm{kg}$ ), Brassica nigra was somewhat beneficial to cortico-hippocampal dependent cognition and working memory, but at a higher dose $(200 \mathrm{mg} / \mathrm{kg})$, it impacts negatively. These results suggest that Brassica nigra might act as a "doubleedged sword". The possibility that alteration of normal mitochondrial redox and glucose bioenergetics dysfunction initiated by high doses of Brassica nigra is responsible for the impaired performance of treated rats in the $\mathrm{Y}$ maze recorded in this study. The biochemical indices monitored in the brain are useful "markers" for assessment of tissue integrity. The measurement of activities of various enzymes in the tissues and body fluids plays significant role in disease investigation and diagnosis. Tissue enzymes can also indicate cellular damage caused by chemical compounds in the extract long before structural damages that can be picked up by conventional histological techniques. In the absence of oxygen, the brain derives its required ATP through anaerobic glycolysis and LDH is needed for the conversion of lactate to pyruvate. $\mathrm{LDH}$ is expressed extensively in body tissues. It is released during tissue damage. ${ }^{[14]} \mathrm{LDH}$ levels in the prefrontal cortex was significantly increased in animals that received Brassica nigra extract at $200 \mathrm{mg} / \mathrm{kg}$ doses) when compared with the control. This is indicative for the tissue damage and might be the reason for the poor performance in the $\mathrm{Y}$ maze spontaneous alternation test observed in this group (200 $\mathrm{mg} / \mathrm{kg}$ ). Its level in animals that received the extract at a milder dose $(100 \mathrm{mg} / \mathrm{kg})$ also showed an increase, but it was not enough to be statistically significant in comparison to the control group. It was however observed that the levels of LDH enzyme in Group C animals, which received the low dose $(50 \mathrm{mg} / \mathrm{kg})$ of the extract, were relatively at par with the control animals. This increase in the activity of LDH indicates an increase in carbohydrate metabolism for energy production via the glycolytic pathway. Malondialdehyde (MDA) is a marker for lipid peroxidation that indicates the oxidative degradation of lipids. It is the process in which free radicals "steal" electrons from the lipids in cell membranes, caused by cellular damage. MDA levels increased in the treated groups with increasing dose of Brassica nigra extract $(50 \mathrm{mg} / \mathrm{kg}, 100 \mathrm{mg} / \mathrm{kg}$, and $200 \mathrm{mg} / \mathrm{kg}$ ), when compared with the control group, 
although it did not reach to the significance levels. This observation, is contradictory to the results of Kiasalari et al. who showed a decrease in the level of MDA in brain tissues. ${ }^{[15]}$

Since superoxide is one of the main reactive oxygen species in the cell. SOD serves a key antioxidant role. SOD decreases oxidative stress and generation of the reactive oxygen species. Therefore, inhibition of the endothelial activation indicates modulation of factors that govern adhesion molecule expression and leukocyte-endothelium interactions. While SOD levels display enhancement in animals treated with the low $(50 \mathrm{mg} / \mathrm{kg}$ body weight) and medium $(100 \mathrm{mg} / \mathrm{kg}$ body weight $)$ doses of the extract in comparison to the control, it showed a significant reduction in animals receiving the high $(200 \mathrm{mg} / \mathrm{kg})$ dose. The former $(50 \mathrm{mg} / \mathrm{kg}$ and $100 \mathrm{mg} / \mathrm{kg})$ gives truth to the claim that Brassica nigra has antioxidative properties. ${ }^{[1,1,1]}$ This result however, further suggests that Brassica nigra exhibits some degree of paradoxical functional facilitation i.e. it is detrimental at a high dose, but is potentially beneficial at a low to medium dose. Kiasalari et al. observed that SOD level increased in animals treated with $150 \mathrm{mg} / \mathrm{kg}$ body weight of hydro-alcoholic Brassica nigra seeds extract in their experiment on evaluating the antiepileptic and antioxidant effect of Brassica nigra on pentylenetetrazolinduced kindling mice. ${ }^{[15]}$

Our observations on the neuronal morphology in the prefrontal cortical region suggest appropriate and normal functionality in these animals since, from the functional point of view, these neurons are the most important cells of the brain. ${ }^{[18]}$ Brassica nigra seeds extract at 200 $\mathrm{mg} / \mathrm{kg}$ body weight induced microarchitectural damages in the adult group presented with properties of early stage apoptosis as apoptotic cells are characterized by karyolysis and pyknosis. ${ }^{[19]}$ On histologic examinations with classical staining, degenerating neurons were recognized by their characteristics appearances in animals treated with $200 \mathrm{mg} / \mathrm{kg}$ doses of the extract. Similar neuronal apoptotic bodies have been previously described consisting of cytoplasm with tightly packed organelles, with or without a nuclear fragment. ${ }^{[20]}$ Cresyl fast violet staining for Nissl substance revealed a reduction in the staining intensity across all Basilica nigra treated groups when compared with the control. This is suggestive of decreased synthesis of proteins by the rough endoplasmic reticulum in the cells.

\section{Conclusion}

Brassica nigra's appetite stimulating property was observed in this study. The present research also indicated that Brassica nigra is not totally innocuous. At the high (200 $\mathrm{mg} / \mathrm{kg}$ ) doses, the crude aqueous extract of the seeds have insulting effects on the prefrontal cortex microarchitecture of adult albino Wistar rats, as well as the expression and activities of certain enzymes, most probably due to the generation of free radicals and oxidative stress.

\section{References}

1. Duke JA, Bogenschutz-Godwin MJ, duCellier G, Duke PK. Handbook of medicinal herbs. New York (NY): CRC Press; 2000. p. 95-6.

2. Felter HW. Monographs extracted from: the eclectic materia medica, pharmacology and therapeutics 1922. Bisbee (AZ): Southwest School of Botanical Medicine; 2001. p. 412-5.

3. Khan BA, Abraham A, Leelamma S. Antioxidant effects of curry leaf, Murraya koenigii and mustards seeds, Brassica juncea in rats fed with high diet. Indian J Exp Biol 1997; 35:148.

4. Joadar A, Das S. Effect of fatty acids isolated from edible oils like mustard, linseed or coconut on astrocytes maturation. Cell Mol Neurobiol 2007;27:973

5. Billman GE. The effects of omega-3 polyunsaturated fatty acids on cardiac rhythm: a critical assessment. Pharmacol Ther 2013;140: 53-80.

6. Yang Y, Raine A. Prefrontal structural and functional brain imaging findings in antisocial, violent, and psychopathic individuals: a metaanalysis. Psychiatry Res 2009;74:81-8.

7. Anderson SW, Bechara A, Damasio H, Tranel D, Damasio A.R. Impairment of social and moral behavior related to early damage in human prefrontal cortex. Nat Neurosci 1999;2:1032-7.

8. Inyang JI, Aniekan-Augusta OE, Olajide TM, Essien A. Effects of ethanolic extract of Brassica juncea (mustard seed) on the brain and kidney tissues of albino Wistar rats. Journal of Biology, Agriculture and Healthcare 2014;22:75-82.

9. Fischer AH, Jacobson K, Rose J, Zeller R. Hematoxylin and eosin staining of tissue and cell sections. Cold Spring Harb Protoc 2008; 3:5.

10. Kadar A, Wittmann G, Liposits Z, Fekete C. Improved method for combination of immunocytochemistry and Nissl staining. J Neurosci Methods 2009;184:115-8.

11. Leung AY. Encyclopedia of common natural ingredients used in food, drugs, and cosmetics. New York (NY): Wiley; 1980.

12. Fulton S. Appetite and reward. Front Neuroendocrinol 2010; 31:85103.

13. Kumar M, Sharma S, Vasudeva N. In vivo assessment of antihyperglycemic and antioxidant activity from oil of seeds of Brassica nigra in streptozotocin-induced induced diabetic rats. Adv Pharm Bull 2013;3:359-65.

14. Selwood T, Jaffe EK Dynamic dissociating homo-oligomers and the control of protein function. Arch Biochem Biophys 2012;519: 131-43.

15. Kiasalari Z, Khalili M, Roghani M, Sadeghian A. Antiepileptic and antioxidant effect of Brassica nigra on pentylenetetrazol-induced kindling in mice. Iran J Pharm Res 2012;11:1209-17.

16. Badrul AM, Sarowar HM, Ekramul HM. Antioxidant and antiinflammatory activities of the leaf extract of Brassica nigra. Int J Pharm Sci Res 2012; 2:303-10. 
17. Rajamurugan R, Selvaganabathy N, Kumaravel S, Ramamurthy CH, Sujatha V, Thirunavukkarasu C. Polyphenol contents and antioxidant activity of Brassica nigra (L.) Koch. leaf extract. Nat Prod Res 2012;26:2208-10.

18. Coward LA. Neuron physiology. Towards a theoretical neuroscience: from cell chemistry to cognition. In: Cutsuridis V, Taylor
JG, editors. Springer series in cognitive and neural systems. Vol 8 . New York (NY): Springer; 2013. p. 53-95.

19. Osten P, Margrie TW. Mapping brain circuitry with a light microscope. Nat Methods 2013;10:515-23.

20. Stefanis L, Burke RE, Greene LA. Apoptosis in neurodegenerative disorders. Curr Opin Neurol 1997;10: 299-305.

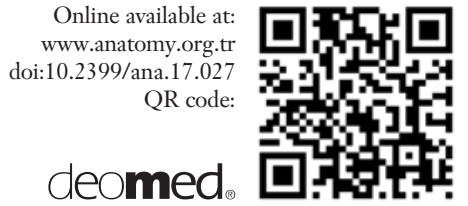

Correspondence to: Tolulope Timothy Arogundade, PhD Department of Anatomy, Faculty of Basic Medical Sciences, Adeleke University, Ede, Nigeria

Phone: +234803 7165263

e-mail: arogundadetolulope@gmail.com

Conflict of interest statement: No conflicts declared.

This is an open access article distributed under the terms of the Creative Commons Attribution-NonCommercial-NoDerivs 3.0 Unported (CC BY-NCND3.0) Licence (http://creativecommons.org/licenses/by-nc-nd/3.0/) which permits unrestricted noncommercial use, distribution, and reproduction in any medium, provided the original work is properly cited. Please cite this article as: Arogundade TT, Enaibe BU, Adigun OO, Adigun FM, Gbadamosi IT. Dose-dependent effect of black mustard seeds (Brassica nigra) extract on the prefrontal cortex of adult Wistar rats. Anatomy 2017;11(3):107-114. 